Original Research Paper

\title{
Pembangunan Aplikasi Mudah Alih "Pocket Lingua Sign" Untuk Pembelajaran Bahasa Isyarat
}

\author{
Farah Izzati Md Rashid ${ }^{1}$, Mohd Hishamuddin Abdul Rahman² \\ ${ }^{1}$ Program of ISMP (Multimedia), Department of Computing. Faculty of Art, Computing \\ \& Creative Industry. Universiti Pendidikan Sultan Idris. Tanjong Malim, Malaysia. \\ ${ }^{2}$ Department of Computing. Faculty of Art, Computing \& Creative Industry. Universiti \\ Pendidikan Sultan Idris. Tanjong Malim, Malaysia.
}

Article History
Received:
15.10 .2021
Revised:
20.11 .2021
Accepted:
10.12 .2021
*Corresponding Author:
Mohd Hishamuddin Abdul
Rahman
Email:
mhishamuddin@fskik.upsi.edu.my

This is an open access article, licensed under: $\mathrm{CC}-\mathrm{BY}-\mathrm{SA}$

\begin{abstract}
Abstrak: Aplikasi Pocket Lingua Sign ini merupakan satu aplikasi yang dibangunkan untuk membantu masyarakat yang ingin mempelajari dan memahami Bahasa isyarat pada peringkat awal. Perkara ini juga memberi pendedahan kepada orang yang kurang mengetahui berkenaan bahasa isyarat. Untuk projek ini, sistem ini menggunakan model ADDIE. Antara kelebihan menggunakan model ADDIE ini ialah dapat menyusun projek ini mengikut kerangka masa yang ditetapkan. Bedasarkan kaedah analisis yang dilaksanakan projek ini menumpukan kepada pembelajaran asas bahasa isyarat. Pengujian telah dijalankan melalui pengedaran soal selidik di dalam bentuk Goofle Form. Kebanyakan pengguna bersetuju dengan aplikasi ini. Aplikasi Pocket Lingua Sign ini juga menggunakan media interaktif seperti video dan gambar. Hal ini kerana, penggunaan sebegini lebih mempercepatkan proses pemahaman pembelajaran terutama secara visual. Pada masa akan datang, diharapkan aplikasi ini mempunayi lebih banyak maklumat supaya pengguna lebih berpuas hati. Secara kesimpulannya, aplikasi ini dapat memudahkan pengguna untuk mencari bahan maklumat berkenaan bahasa isyarat tangan.
\end{abstract}

Kata Kunci: Alatan Pembelajaran, Aplikasi Mudah Alih, Bahasa Isyarat.

\section{Development of "Pocket Lingua Sign" Mobile Application for Sign Language Learning}

Abstract: This Pocket Lingua Sign application is an application developed to help people who want to learn and understand sign language at an early stage. This also gives exposure to people who do not know much about sign language. For this project, the system uses the ADDIE model. Among the advantages of using this ADDIE model is to be able to organize this project according to a set time frame. Based on the analytical method implemented, this project focuses on the basic learning of sign language. Testing was conducted through the distribution of questionnaires in the form of Goofle Form. Most users agree with this application. The Pocket Lingua Sign application also uses interactive media such as videos and images. This is because, such use speeds up the process of understanding learning, especially visually. In the future, it is hoped that this application has more information so that users are more satisfied. In conclusion, this application can make it easier for users to find information materials regarding hand sign language.

Keywords: Learning Tool, Mobile Application, Sign Language. 


\section{Pendahuluan}

Menurut Pradikja Hendra et al. [1] bahasa isyarat merupakan bahasa yang tidak menggunakan tutur kata daripada lisan manusia atau menggunakan penulisan pada sistem lambang. Bahasa isyarat merupakan satu cara komunikasi dari golongan OKU atau lebih dikenali sebagai "Orang Kelainan Upaya”. Namun, terdapat masyarakat Malaysia yang kurang mendapat pendedahan berkenaan bahasa isyarat. Terdapat juga di antara mereka yang mencuba mempelajari namun mempunyai sumber pencarian yang terhad. Dengan menggunakan platform aplikasi ini dapat membantu pengguna mudah mencari maklumat yang lengkap. Perkara ini juga memberi pendedahan kepada orang yang kurang mengetahui berkenaan bahasa isyarat tersebut. Menurut Khairul [2], pendedahan terhadap bahasa isyarat sememangnya perlu diberikan semenjak kecil lagi.

Selama ini, pengguna hanya mempunyai solusi dengan membeli buku mahupun menggunakan pencarian di internet. Hal ini demikian, mereka perlu mengumpul sendiri maklumat dan menyebabkan pencarian pembelajaran bahasa isyarat mengambil masa yang agak lama dan sukar mencari sumber pembelajaran yang lengkap. Perkembangan teknologi perlu dimanfaatkan hal ini kerana ianya dapat mempermudahkan dan mempercepatkan masa pekerjaan seseorang semasa mengakses. Perkara ini juga memudahkan pengguna memperoleh informasi yang diperlukan dengan cepat dan mudah [3].

Dengan adanya penggunaan aplikasi bahasa isyarat ini dapat mengurangkan lagi masa pencarian maklumat. Hal ini disebabkan, kurangnya platform bahasa isyarat di internet yang menyukarkan lagi pencarian. Menurut Wijayanti \& Mulyati [4] proses pencarian maklumat boleh berlaku melalui medium berperantara seperti internet, televisyen dan lain-lain. Seperti yang diketahui, sumber di dalam Internet menunjukkan maklumat yang tidak menyeluruh. Sebagai contoh pencarian yang disediakan hanyalah seperti pembelajaran abjad dan nombor. Pengguna tidak dapat mencari pembelajaran seterusnya dan memerlukan bimbingan dalam pencarian pembelajaran yang seterusnya.

\section{Kajian Literatur}

Dalam kajian literatur terkandung maklumat mengenai tinjauan literatur yang bersesuaian, kajian ke atas produk lampau, kelebihan dan kekuatan produk yang digunakan berbanding produk semasa.

\subsection{Bahasa Isyarat kepada Pengguna}

Komunikasi itu sendiri berasal dari bahasa Latin, iaitu communication yang memberi maksud pemberitahuan atau pertukaran [5]. Komunikasi merupakan aspek paling penting dalam aktiviti seharian manusia. Cara untuk memahami percakapan memerlukan komunikasi yang baik. Sekiranya hanya satu pihak menyampaikan dan satu pihak lagi tidak memahami menyebabkan banyak masalah. Komunikasi juga diperlukan untuk meminta bantuan, belajar, mengajar atau sebagai komunikasi harian. Komunikasi tidak hanya terhad melalui lisan sahaja malah melalui bahasa nonverbal iaitu penggunaan bahasa isyarat. Menurut Kusumawati [6] komunikasi nonverbal dapat dilihat berupa lambang-lambang seperti gesture, warna, mimik wajah dan sebagainya. Bahasa isyarat ini juga digunakan untuk kesemua bahasa. Terdapat 2 jenis bahasa isyarat Malaysia iaitu bahasa isyarat Malaysia atau lebih dikenali BIM dan KTMB iaitu Kod Tangan Bahasa Melayu. Bahasa Inggeris pula umumnya kepada 2 iaitu ASL iaitu America Sign Language dan BSL iaitu "British Sign Language".

Terdapat pelbagai platform yang boleh digunakan untuk mencari maklumat berkaitan bahasa isyarat itu sendiri. Terutamanya boleh digunakan di dalam internet, youtube, buku online mahupun pembelajaran secara online. Menurut Delfanti et al. [7], dibuat suatu aplikasi yang dapat mempermudahkan untuk mendapatkan maklumat serta memahami definisi mobile dari istilah tersebut dengan memanfaatkan teknologi mobile yang berkembang pesat saat ini. Aplikasi bahasa Isyarat Bahasa Melayu terdapat platform rasmi yang digunakan di Malaysia iaitu Mybim. Platform ini diwujudkan pada tahun 2018 kepada Persekutuan Orang Pekak Malaysia atau nama ringkasnya MFD (Malaysian Federation of the Deaf). Platform ini juga banyak membantu OKU di Malaysia dengan penjualan buku, isu semasa, pembelajaran secara online mahupun aplikasi yang menyediakan maklumat bahasa isyarat. Aplikasi Mybim dan Pocket Lingua Sign ini dapat dibezakan dengan penggunaan nota bukan hanya melalui gambar malah disediakan video untuk mempermudahkan lagi kefahaman. Setiap Platform yang diwujudkan ini banyak membantu semua pengguna. Malah, aplikasi mahupun laman web dapat digunakan pada setiap masa dan dimana sahaja dengan hanya menggunakan telefon pintar.

Buku merupakan sumber bacaan yang digunakan oleh semua golongan umur untuk pelbagai kegunaan. Sebagai contoh, buku banyak digunakan untuk sistem pendidikan terutamanya dalam pembelajaran bahasa Isyarat. Kementerian Pembelajaran Malaysia (KPM) juga menyediakan buku teks untuk mempelajari bahasa isyarat. Buku bertaraf dunia sedang diusahakan oleh pihak KPM. Sebagai 
contoh, buku yang mempunyai ciri-ciri teknologi, berkualiti serta mesra pengguna. Seiring dengan kemajuan teknologi, nilai-nilai murni masih diterapkan bagi mewujudkan insan yang bersahsiah dan cemerlang [8]. Namun, dalam kepesatan globalisasi negara Malaysia pastinya tidak mahu ketinggalan dalam menggunakan bahan rujukan secara online. Dengan kegunaan aplikasi ini dalam bidang pendidikan mahupun sebaliknya menjadikan lebih menarik malah mudah digunakan. Pembelian buku juga memakan nilai wang ringgit sedangkan penggunaan aplikasi tidak memerlukan membayar dengan harga yang mahal [9]. Hal ini demikian, pengguna lebih memilih penggunaan yang lebih mudah sejajar dengan peredaran zaman.

\subsection{Bahasa Isyarat Menggunakan Aplikasi}

Terdapat sesetengah pengguna yang berminat untuk mempelajari bahasa Isyarat secara lebih mendalam. Pendedahan kurang diberikan kepada mereka menyebabkan mereka kurang mengetahui cara mencari bahan mahupun pembelajaran awal. Pengguna perlu mencari cara untuk mendapatkan bahan bahasa Isyarat tersebut.

Masih ramai yang memberi tanggapan bahasa Isyarat hanya perlu dipelajari oleh golongan OKU iaitu "Orang Kelainan Upaya" sahaja. Hal ini disebabkan, mereka tiada ahli keluarga yang tergolong dengan masalah pendengaran dan pertuturan. Menurut Mandarani \& Putra [10], aplikasi bahasa isyarat ini dapat memberikan kemudahan kepada pengguna untuk belajar bahasa isyarat. Dengan aplikasi ini secara tidak langsung membuka mata pengguna bahawa bahasa Isyarat ini dapat menambah pengetahuan baru dan banyak membantu dalam komunikasi bersama mereka.

Salah satu bahasa isyarat menggunakan aplikasi adalah ASL App. ASL App merupakan aplikasi bahasa Isyarat yang menunjukkan bahan bahasa Isyarat dalam bahasa Inggeris. Aplikasi ini diperkenalkan pada tahun 2015 dan ditunjukkan dalam bentuk lebih daripada 2000 video. Ianya direka untuk menjadikan pembelajaran mudah diakses dan menyenangkan perbualan dengan pelbagai ciri-ciri yang ditunjukkan. Menurut Aziz et al. [11] aplikasi ASL app hanya menyediakan aplikasi dalam bahasa Inggeris iaitu American Sign Language. Bahasa isyarat ASL (American Sign Language) merupakan bahasa isyarat dimana bahasa isyarat ini merupakan bahasa isyarat internasional yang banyak menjadi landasan untuk bahasa isyarat lain di dunia [12].

Pelbagai penggunaan aplikasi yang semakin meluas dipasarkan terutamanya dalam bidang permainan, penjualan mahupun buku secara online di serata dunia. Pasaran ini tidak hanya terhad kepada penggunaan sesebuah negara sahaja malah dibuka ke seluruh negara. Penggunaan aplikasi bahasa isyarat ini menjadi peluang untuk digunakan di mana-mana sahaja. Aplikasi offline dan online merupakan 2 jenis aplikasi di dalam smartphone [13]. Aplikasi ini juga dapat digunakan secara online dan offline di mana memudahkan pengguna untuk menggunakannya di mana sahaja berada.

\subsection{Jenis Platform untuk Bahasa Isyarat}

Platform bahasa isyarat dapat dibahagikan kepada bahasa isyarat menggunakan sosial media, bahasa Isyarat menggunakan Laman Web dan Youtube. Platform Bahasa isyarat ini lebih menekankan kepada sistem operasi dari peringkat mobile [1]. Menurut Sandi et al. [14], penggunaan telefon pintar samaada Android mahupun iOS yang meningkat sepanjang tahun menjadikan mereka memilih platform ini sebagai asas dalam penggunaan sesebuah aplikasi. Helmond [15] turut mengatakan istilah "platform" telah menjadi konsep dominan untuk syarikat media sosial kerana memposisikan diri di pasaran dan menangani pengguna, dan telah banyak digunakan oleh pengguna dan akhbar. Jenis platform ini banyak membantu dalam pencarian pengguna mencari bahasa Isyarat.

\subsubsection{Bahasa Isyarat Menggunakan Sosial Media}

Menurut Sagiyanto \& Ardiyanti [16], sosial media ialah kelompok aplikasi asas dalam penggunaan media internet. Media sosial bagi Irwandani \& Juariyah [17] pula berpendapat bahasa isyarat yang efektif dan efisyen yang dihasilkan melalui penggunan sosial media. Perkembangan sosial media semakinmeningkat penggunaan setiap tahun. Hal ini berlaku kerana masyarakat ingin mengikuti perkembangan semasa dan mereka mula meminati medium seperti itu [18]. Mempelajari bahasa isyarat telah secara lebih meluas termasuk di medium seperti di Instagram. Sosial media bukan menjadi penghalang malah membuka peluang kepada pengguna yang ingin belajar melalui tontonan daripada Instagram.

Menurut Fitria [19], tidak kira pengguna Ios atau Android, aplikasi menjadi satu aplikasi yang popular di kalangan pengguna. Instagram juga merupakan media sosial yang pada dasarnya berfungsi untuk mengambil gambar mahupun vídeo untuk dikongsikan kepada sesama pengguna [20]. Instagram 
diperkenalkan pada tahun 2010. Pada awalnya Instagram lebih menumpukan kepada penggunaan sosial. Namun, setiap tahun penggunaan semakin meningkat dan menjadikan Instagram sebagai pusat kreativiti dengan mempunyai pendedahan kepada tempat pembelian, penjualan mahupun tempat mencari bahan seperti bahasa isyarat. Walaupun, Instagram bukan sebuah tempat untuk bahan mencari rujukan dan pembelajaran. Populariti yang meningkat memberikan peluang kepada pengguna untuk menonjolkan kreativiti mahupun memberikan pendedahan seperti bahasa isyarat kepada pengguna yang ingin mempelajarinya. Instagram juga memperoleh 100,000 pengikut dan satu juta pengguna hanya dalam dua bulan dan dua minggu selepas pembukaan pertama.

Berikut merupakan salah satu akaun yang yang menyediakan maklumat berkenaan bahasa isyarat melalui video mahupun gambar.

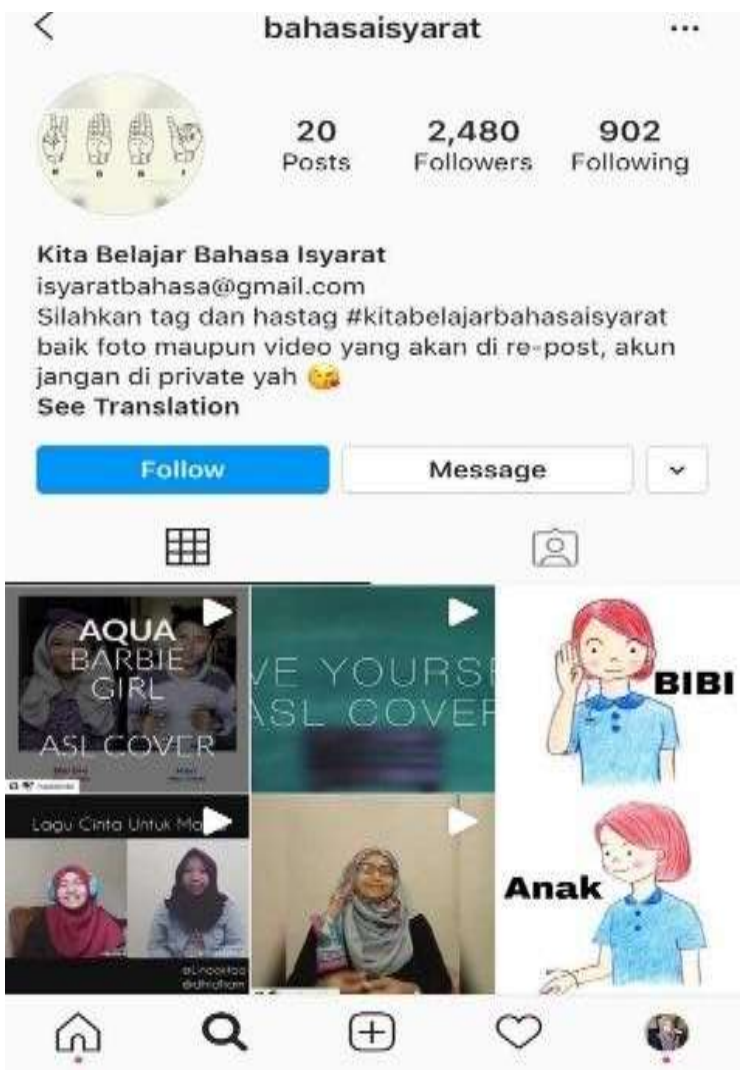

Rajah 1. Bahasa Isyarat menggunakan Platform Instagram

\subsubsection{Bahasa Isyarat menggunakan Laman Web}

Menurut Hussin et al. [21] menjelaskan laman web menyediakan pelbagai platform yang tidak terhad kepada bentuk grafik sahaja malah teks, animasi audio mahupun video banyak terdapat di web tersebut. Laman web merupakan satu kegunaan yang banyak memberikan maklumat kepada pengguna. Pengguna akan sentiasa menggunakan laman web dalam pelbagai carian. Laman web dapat dikategorikan seperti Google, Chrome, Internet Explorer dan sebagainya. Hal ini kerana, laman web merupakan satu kaedah yang mudah dalam mencari maklumat. Menurut Mohammad Jaffar \& Sha'ari [22], penggunaan laman web (www) mula diperkenalkan sejak lebih 15 tahun yang lalu, tetapi penggunaan alat telekomunikasi dalam pembelajaran bermula sejak kira-kira sembilan tahun yang lalu.

Penggunaan laman web ini juga banyak digunakan oleh pengguna di sebabkan mereka tidak perlu memulakan pencarian bahan bahasa isyarat di kedai mahupun di perpustakaan. Pencarian bahan di laman sesawang boleh memberikan kepuasan dalam mencari bahan yang diperlukan dalam masa dan kos yang tidak terlalu banyak. 


\section{PERSEKUTUAN ORANG PEKAK MALAYSIA MALAYSIA FEDERATION OF DEAF}

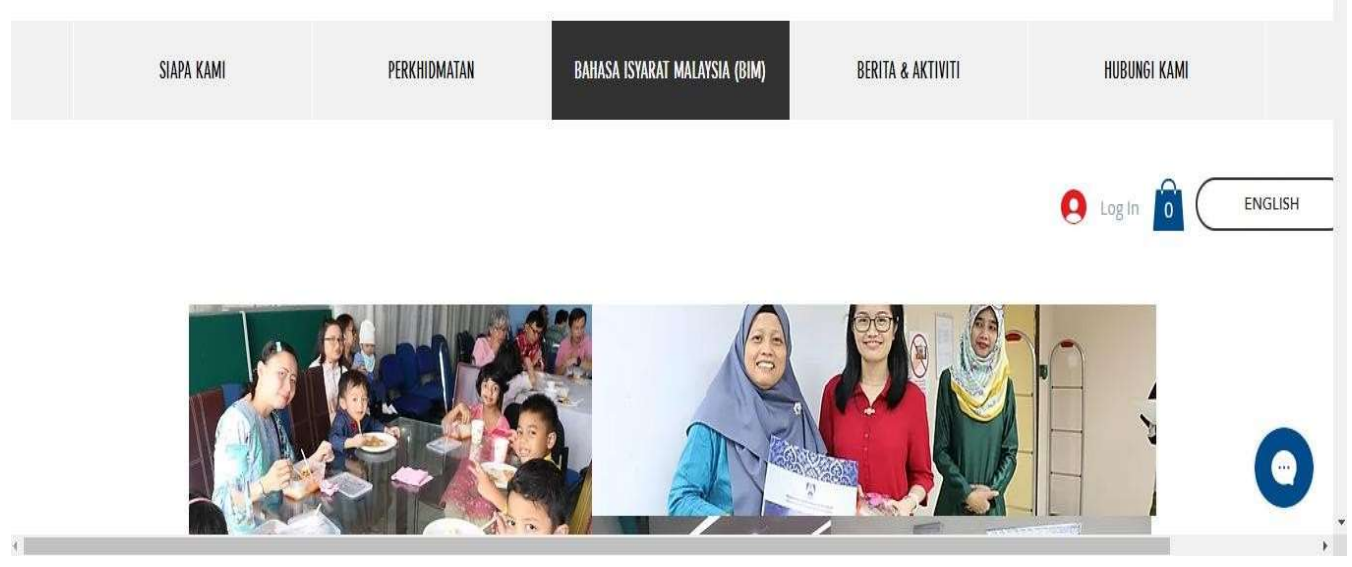

Rajah 2. Bahasa Isyarat menggunakan Website

\subsubsection{Bahasa Isyarat menggunakan Youtube}

Menurut Arofah [23], Youtube adalah media baru berjenis user generated content atau media dimana konten diciptakan oleh pengguna media itu sendiri. Youtube juga sebagai salah satu rujukan atau tutorial untuk mendapatkan informasi [24]. Youtube merupakan paparan video yang diketahui di seluruh negara.

Secara umumnya, YouTube ialah sebuah laman web video Amerika Syarikat yang beribu pejabat di San Bruno, California dan telah dicipta pada Februari 2005. YouTube kini telah beroperasi sebagai salah satu anak syarikat Google. Pelbagai video telah disediakan di Youtube dari video masakan, nyanyian, dokumentasi, tarian mahupun video pembelajaran. Menurut Bagut [25], Youtube dipilih sebagai sumber pencarian data hal ini kerana ianya merupakan salah satu pencarian web di internet (interconnectionnetworking) yang menyediakan berbagai macam video mulai dari video klip lagu sehingga ke berbentuk film, serta video-video yang dibuat pengguna youtube itu sendiri. Pendaftaran di youtube secara percuma memberikan pengguna lebih banyak peluang mendapatkan bahan bahasa isyarat tersebut. Laman web ini membenarkan para pengguna untuk memuat naik, menonton, menilai ulas, berkongsi, menambahkan ke kegemaran, melaporkan dan memberi komen kepada kandungan video tersebut. Hal ini menyebabkan, YouTube adalah video online yang dapat digunakan untuk media pembelajaran [26].

\subsection{Faktor Penggunaan Aplikasi Bahasa Isyarat}

Terdapat dua faktor yang dikenalpasti yang mempengaruhi pembangunan sebuah aplikasi bahasa isyarat, iaitu:

1. Keberkesanan Kos

2. Interaktif

\subsubsection{Keberkesanan Kos}

Media sosial adalah satu medium yang ssangat sesuai untuk menjalankan pelbagai kegiatan sama ada pembelajaran, penjualan, kegunaan sosial media dan sebagainya. Namun, kegunaan bahasa isyarat tangan ini di aplikasi sangat menjimatkan kos. Menurut Ramdan et al., [27], platform digital memberi peluang kepada perniaga mahupun pengguna untuk berkongsi maklumat mahupun menjalankan perniagaan. Hal ini menjimatkan lagi masa dan kos mereka.

Penggunaan aplikasi ini juga memberi kesan positif kepada pengguna kerana mereka tidak perlu membuang masa mencari maklumat. Maklumat yang disediakan juga tersusun memudahkan lagi pencarian maklumat. Media social merupakan satu platform yang murah dan mudah untuk memperoleh maklumat terutamanya dalam bahasa isyarat. Menurut Surahman \& Setiawan [28], Aplikasi mudah alih adalah satu aplikasi yang mudah seiring usaha melakukan media sosial dengan menggunakan peralatan seperti telefon bimbit dan sebagainya. 


\subsubsection{Interaktif}

Sistem maklumat dianggap Berjaya apabila berlaku hubungan di antara manusia dengan teknologi. Laman web merupakan salah satu medium interaktif yang muncul buat kali pertama pada awal dahulu. Mengikuti peredaran masa mobile aplikasi melonjak naik seiring bersama teeknologi yang lain. Pengguna boleh menggunakan aplikasi bahasa isyarat ini untuk mencari maklumat yang menjadikan ianya satu ciri interaktif yang baik. Hal ini demikian, aplikasi ini membina kepercayaan terhadap pengguna. Kemajuan teknologi komunikasi seperti telefon television, internet, dan komputer tidak dapat dihindari. Hal ini demikian kerana kita hidup sejajar dengan kemajuan teknologi dan ilmu pengetahuan.

\section{Metodologi Kajian}

\subsection{Model ADDIE}

Beberapa model yang digunapakai dalam membangunkan sebuah aplikasi, iaitu ADDIE [29] [30] [31], Evolutionary Prototype Model [32], Rapid Application Development [33], Rapid Prototyping [34], waterfall [35], Multimedia Development Life Cycle [36] [37], Prototyping [38] [39], Object Oriented Analysis and Design [40]. Pada penelitian ini digunakan model ADDIE. Rajah 3 menunjukkan model ADDIE yang digunakan.

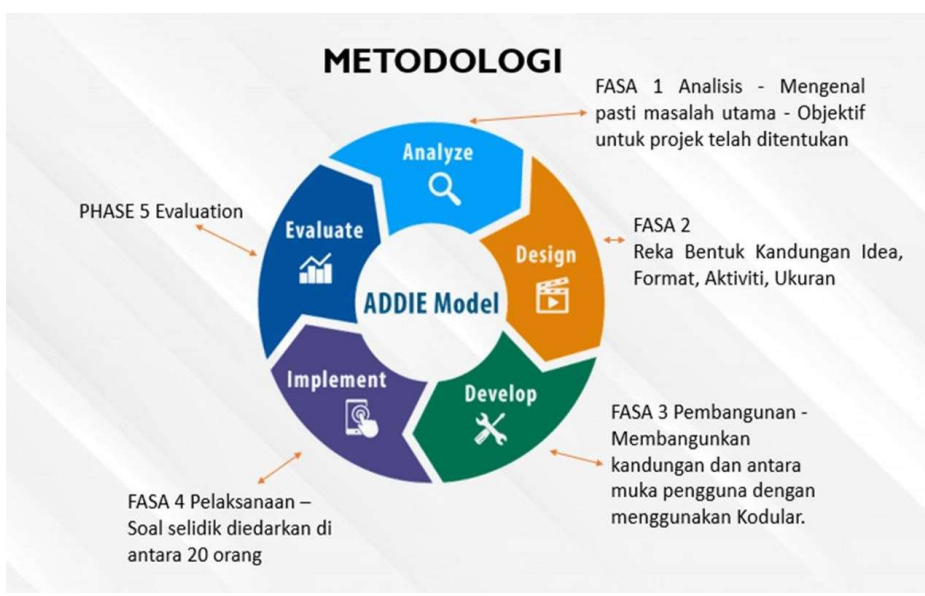

Rajah 3. Model ADDIE

Lima fasa yang terdapat dalam model ADDIE ialah:

1. Analisis (Analyze)

2. Reka Bentuk (Design)

3. Pembangunan (Development)

4. Implementasi (Implementation), Dan

5. Evaluasi (Evaluation).

Pada fasa yang pertama merupakan fasa analisis di mana ianya menggunakan sumber untuk di analisis. Analisis juga untuk mengenal pasti masalah utama dan menentukan objektif projek yang telah ditentukan. Seterusnya diteruskan dengan fasa kedua iaitu reka bentuk di mana reka bentuk kandungan ini menumpukan kepada reka papan cerita prototype, interface dan sebagainya. Fasa ketiga pula pembangunan membangunkan kandungan dan antara muka pengguna dengan menggunakan kodular. Di samping itu, di Fasa keempat iaitu perlaksanaan dimana borang soal selidik telah diedarkan di antara 30 orang dari setiap lapisan masyarakat. Malah, menggambarkan perkembangan dan pelaksanaan projek dijalankan. Fasa terakhir merupakan fasa evaluasi dimana ia ditentukan dengan keberhasilan aplikasi sama ada berjaya atau tidak berjaya dengan dilakukan pengujian.

Jadual 1 menerangkan perincian mengenai model ADDIE yang digunakan. 


\section{Jadual 1. Perincian Model ADDIE}

\begin{tabular}{|c|c|c|}
\hline Fasa & Tugas & Hasil \\
\hline $\begin{array}{l}\text { Analisis } \\
\text { (Analyze) }\end{array}$ & $\begin{array}{l}\text { a. Menentukan objektif projek } \\
\text { b. Menganalisis perisian dan } \\
\text { keperluan. } \\
\text { c. Menentukan kesesuaian } \\
\text { kepada pengguna }\end{array}$ & a. Analisis hasil tinjauan \\
\hline $\begin{array}{l}\text { Reka Bentuk } \\
\text { (Design) }\end{array}$ & $\begin{array}{l}\text { a. Reka bentuk reka papan } \\
\text { cerita } \\
\text { b. Membangunkan prototaip }\end{array}$ & $\begin{array}{l}\text { a. Penggunaan gambar } \\
\text { rajah. } \\
\text { b. Penggunaan Blok } \\
\text { c. Papan Cerita Reka } \\
\text { Bentuk }\end{array}$ \\
\hline $\begin{array}{l}\text { Pembangunan } \\
\text { (Development) }\end{array}$ & $\begin{array}{l}\text { a. membangunkan kandungan } \\
\text { dan antara muka pengguna } \\
\text { denganmenggunakan } \\
\text { kodular. } \\
\text { b. membuat ujian yang } \\
\text { dihasilkan dan menyebarkan } \\
\text { bahan tersebut. }\end{array}$ & $\begin{array}{l}\text { a. Proses penjanaan dan } \\
\text { penghasilan mobile } \\
\text { aplikasi }\end{array}$ \\
\hline $\begin{array}{l}\text { Implementasi } \\
\text { (Implementation) }\end{array}$ & $\begin{array}{l}\text { a. Soal selidik diedarkan kepada } \\
30 \text { orang dari setiap lapisan } \\
\text { pengguna. }\end{array}$ & $\begin{array}{l}\text { a. Pengedaran borang soal } \\
\text { selidik }\end{array}$ \\
\hline $\begin{array}{c}\text { Evaluasi } \\
\text { (Evaluation) }\end{array}$ & $\begin{array}{l}\text { a. keberhasilan aplikasi sama } \\
\text { ada berjaya atau tidak } \\
\text { berjaya dengan dilakukan } \\
\text { pengujian. } \\
\text { b. Uji sistem menggunakan } \\
\text { Ujian Kefungsian }\end{array}$ & $\begin{array}{l}\text { a. Kefungsian danUjian } \\
\text { TerhadapPengguna }\end{array}$ \\
\hline
\end{tabular}

Dalam pembangunan aplikasi ini, terdiri dari pelakon (actor), hubungan (relationship) dan use case. Pelakon (actor), bertindak sebagai mewakili apa sahaja yang berinteraksi dengan sistem. Ianya bukan sebahagian daripada sistem. Manakala use case pula Tindakan yang dilakukan oleh sistem (proses). Semua ini dimulakan oleh pelakon untuk melakukan fungsi terhadap sesuatu sistem.

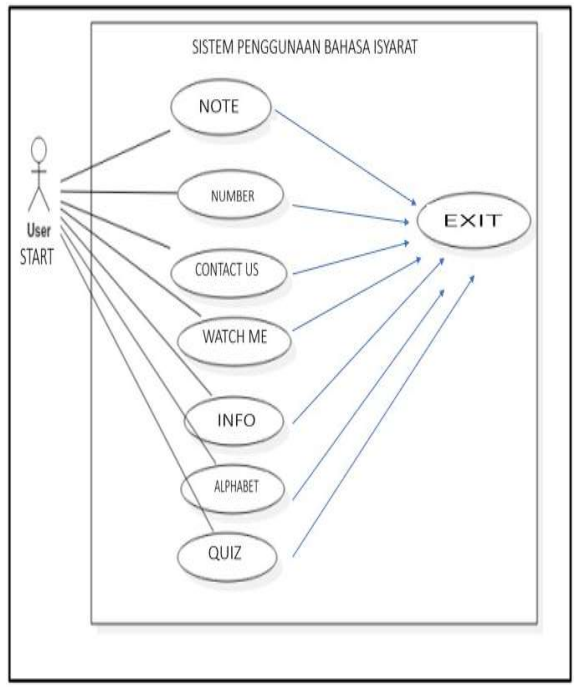

Rajah 4. Diagram: Use Case 
Rajah 4 menunjukkan bahwa aplikasi yang dibangunkan digunakan untuk platform sistem penggunaan bahasa isyarat. Pengguna boleh terus masuk dan memilih antara bahagian Note, Number, Contact Us, Watch Me, Info, Alphabet dan Quiz dimana ianya menghubungkan pengguna ke bahagian yang lebih terperinci. Nota yang diberikan kepada pengguna di dalam bentuk video mahupun gambar. Setelah pengguna belajar bahasa isyarat mereka boleh memasuki bahagian Quiz untuk menilai kefahaman mereka.

\subsection{Papan Cerita Reka Bentuk Antaramuka}

Reka bentuk antara muka adalah untuk menerangkan bagaimana pengguna berinteraksi dengan sistem. Walau bagaimanapun, reka bentuk antara muka ini hanyalah lakaran awal di mana diletakkan sasaran yang ingin dicapai.

Rajah 5(a) menunjukkan laman utama dengan kategori. Halaman ini boleh dibuka oleh semua pengguna. Pada halaman utama tidak diletakkan log masuk, manakala Rajah 5(b) menunjukkan antara muka halaman Number dan Alphabet. Pengguna dapat melihat perincian maklumat yang ditunjukkan.
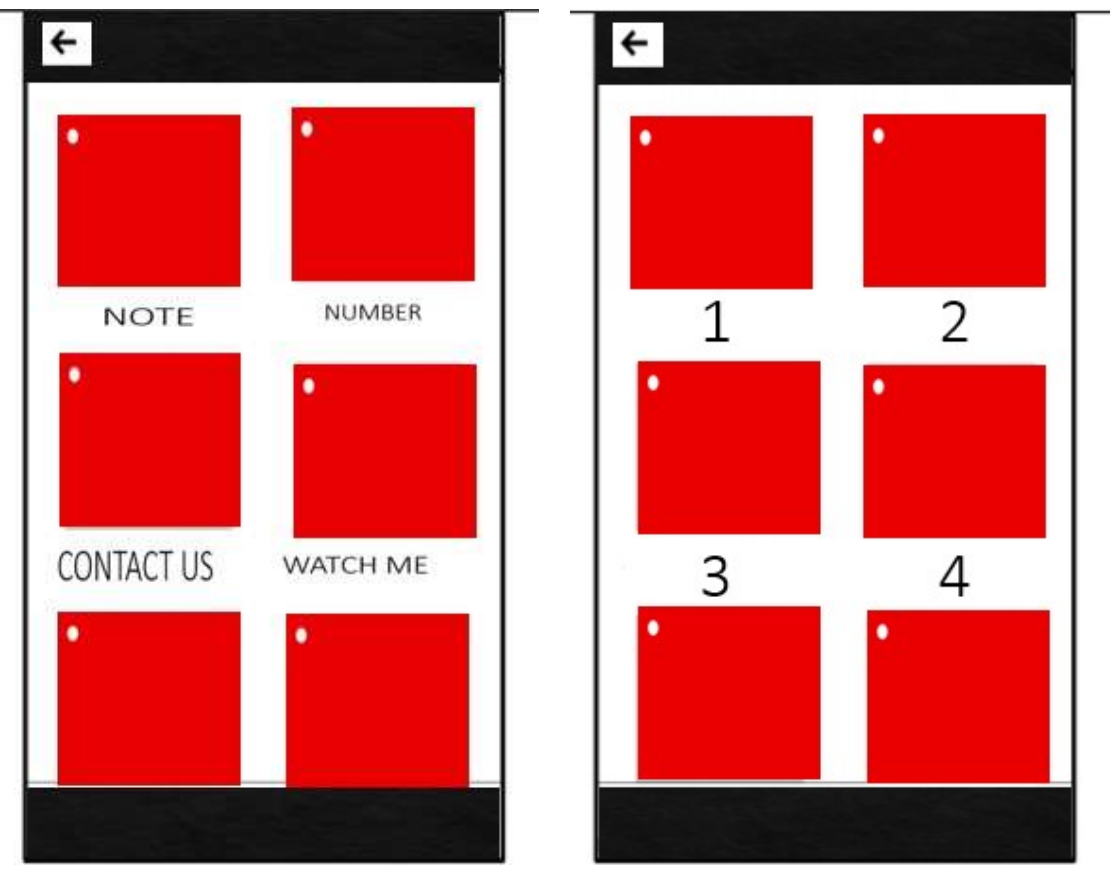

Rajah 5. Papan Cerita Reka Bentuk: (a) Laman Utama, (b) Halaman Number \& Alphabet

\section{Dapatan Kajian dan Analisis}

\subsection{Reka Bentuk Aplikasi}

Antaramuka pengguna adalah salah satu ciri utama di dalam sistem dan sangat penting kepada pengguna. Ianya dijadikan satu tempat sebagai nota, interaksi, mahupun komunikasi. Sesebuah aplikasi pasti memilih untuk tidak menunjukkan kerumitan penggunaan. Pada Rajah 6(a) menunjukkan halaman dimana boleh ditekan button Start untuk mula masuk ke dalam aplikasi Pocket Lingua Sign ini. Setelah menekan butang Start akan terus masuk ke halaman utama seperti yang ditunjukkan pada Rajah 6(b) di mana terdapat 7 button di dalam sistem iaitu Note, Number, contact us, Watch me, Info, Alphabet dan Quiz. Pengguna boleh memilih untuk membuka mana-mana button untuk memulakan pembelajaran bahasa isyarat. Sekiranya pengguna menekan button Note. "Click here" tekan untuk melihat video tersebut. Paparan video selama 2.08 minit menunjukkan video pembelajaran asas bahasa isyarat seperti cara untuk berkomunikasi. Setelah selesai menonton video pengguna boleh menekan button "Home". Pada Rajah 6(c), ditunjukkan paparan maklumat asas ditunjukkan seperti maklumat pensyarah, dan pelajar, email, dan no fon. Pengguna mendapat maklumat asas dan mudah menghubungi sekiranya terdapat masalah pada aplikasi tersebut. Setelah selesai pengguna boleh menekan button "Home". 


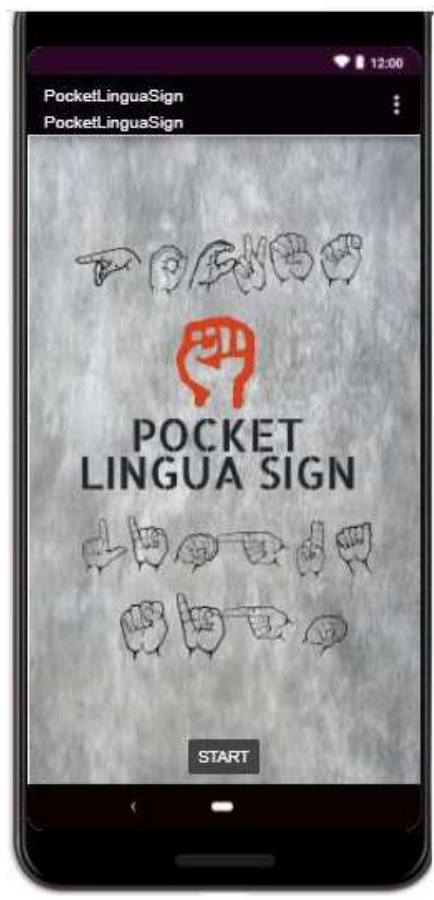

(a)

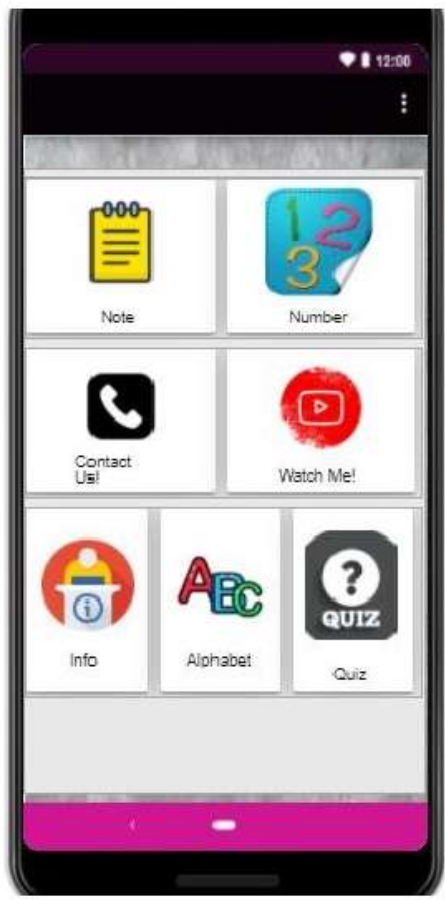

(b)

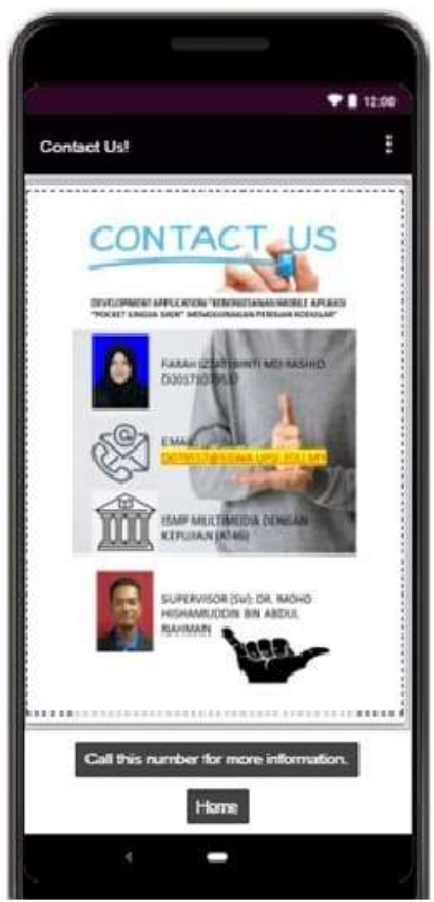

(c)

Rajah 6. Reka Bentuk Aplikasi: Paparan Maklumat

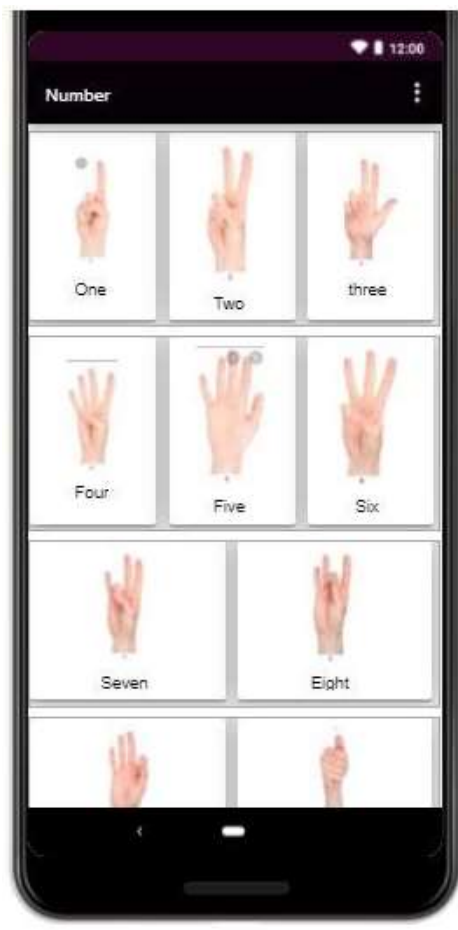

(a)

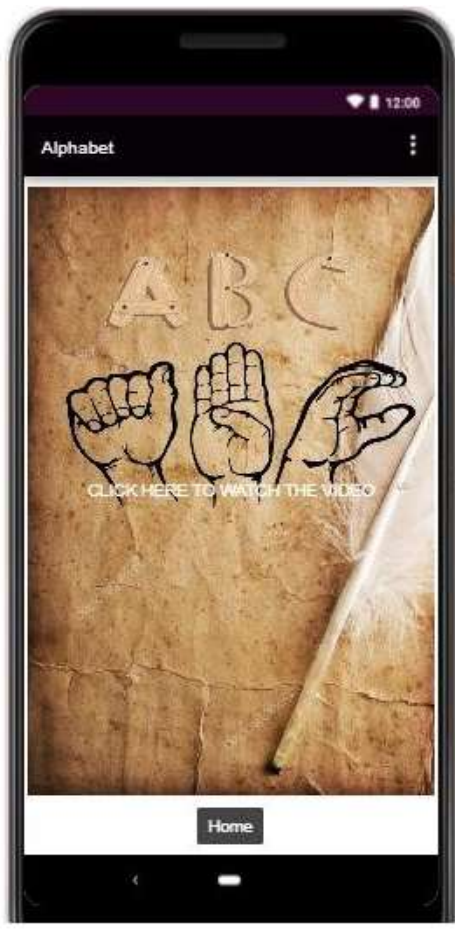

(b)

Rajah 7. Reka Bentuk Aplikasi: Paparan Utama Aplikasi 
Rajah 7(a) menunjukkan halaman Numbering. Pada halaman Numbering ini ditujukkan gambar bahasa isyarat tangan iaitu nombor asas 1 sehingga 10, dan Rajah 7(b) menunjukkan halaman Alphabet iaitu abjad A sehingga Z. Pengguna boleh melihat cara pergerakan tangan yang tepat untuk abjad.

\subsection{Maklum Balas daripada Responden}

Borang soal selidik ini diberikan kepada 30 orang responden tanpa mengira lapisan umur dari setiap lapisan masyarakat. Nilai skor diberikan dari Sangat Tidak Setuju (STS), Tidak Setuju (TS), Tidak Pasti (TP), Setuju (S), dan Sangat Setuju(S). Borang ini juga dapat dibahagikan kepada 3 bahagian iaitu bahagian A (4 soalan), bahagian B (10 soalan) dan bahagian C (10 soalan). Data kajian dikumpulkan melalui instrumen soal selidik menggunakan Google Forms melalui Whatsapp dan Telegram.

Pengkaji menggunakan skala likert dan skor min di dalam borang soal selidik. Tingkat kepuasan pengguna diuji dengan menggunakan Metode Skala Likert. Skala likert ini mempunyai 5 skala iaitu skala sangat tidak setuju (1), tidak setuju (2), tidak pasti(3), setuju (4) dan sangat stuju (5). Jadual 1 menunjukkan pengkelasan skor Min.

Jadual 1. Pengkelasan Skor Min

\begin{tabular}{cc}
\hline $\begin{array}{c}\text { Pengkelasan } \\
\text { Skor Min }\end{array}$ & $\begin{array}{c}\text { Tahap } \\
\text { Penilaian }\end{array}$ \\
\hline $1.00-2.33$ & Rendah \\
\hline $2.34-3.66$ & Sederhana \\
\hline $3.67-5.00$ & Tinggi \\
\hline
\end{tabular}

Jumlah keseluruhan responden adalah 30 orang, jantina perempuan lebih ramai dari lelaki iaitu sebanyak 53.3\% (16 orang) manakala lelaki pula sebanyak 46.7\% (14 orang). Responden yang berumur 21-25 tahun merupakan responden yang paling ramai menjawab soal selidik iaitu sebanyak $76.7 \%$ (23 orang) disertai dengan umur 26-30 tahun $13.3 \%$ (4 orang) dan respon umur 30 tahun ke atas sebanyak $10 \%$ (3 orang).

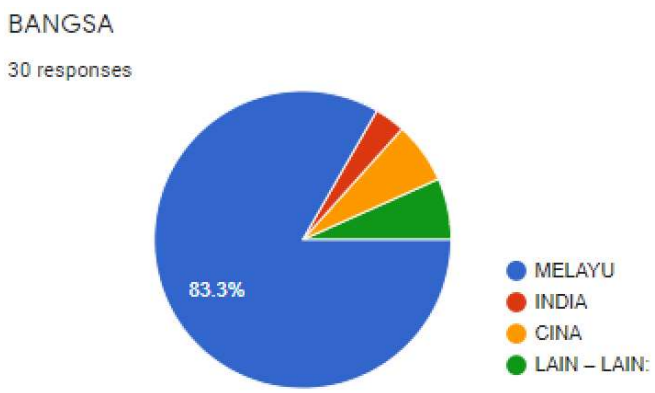

Rajah 8. Demograpi Responden Mengikut Bangsa

Rajah 8 menunjukkan kesemua bangsa menjawab soal selidik diberikan. Majoriti yang menjawab adalah responden berbangsa melayu seramai 25 orang dengan $83.3 \%$. Bangsa India seramai seorang dengan 3.3\%. Manakala, bangsa cina dan lain-lain bangsa seramai 2 orang masing-masing menjadikan peratusan sebanyak $6.7 \%$.

Secara keseluruhannya, pada bahagian B kebanyakan dari responden bersetuju. Namun pada soalan yang ke 6 iaitu kekurangan media interaktif seperti video dan gambar sebagai alat bantuan pembelajaran menunjukkan maklum balas responden yang beragam dari sangat setuju kepada sangat tidak setuju.

Secara keseluruhannya, pada bahagian C kebanyakan dari responden bersetuju. Namun pada soalan yang ke 9: Aplikasi ini memudahkan responden mempelajari bahasa isyarat dan 10: kaedah pembelajaran dan isi kandungan bahasa isyarat yang menarik menunjukkan 2 orang responden sangat tidak setuju dan 2 orang tidak setuju. 
Jadual 2. Kebolehgunaan Mobile Aplikasi "Pocket Lingua Sign"

\begin{tabular}{clcccccc}
\hline NO & \multicolumn{1}{c}{ PERKARA } & (1) & (2) & (3) & (4) & (5) & $\begin{array}{c}\text { SKOR } \\
\text { MIN }\end{array}$ \\
\hline 1 & $\begin{array}{l}\text { Saya setuju bahawa aplikasi ini dapatmenarik minat } \\
\text { dan memberi keseronokan. }\end{array}$ & 0 & 0 & 1 & 6 & 23 & 4.7 \\
\hline 2 & $\begin{array}{l}\text { Kandungan dan reka bentuk aplikasi ini adalah jelas } \\
\text { dan berguna. }\end{array}$ & 0 & 0 & 1 & 4 & 25 & 4.8 \\
\hline 3 & $\begin{array}{l}\text { Aplikasi ini menunjukkan cara untuk mempelajari } \\
\text { bahasa isyarat dari asasseperti huruf dan nombor. }\end{array}$ & 0 & 0 & 2 & 6 & 22 & 4.6 \\
\hline 4 & $\begin{array}{l}\text { Mudah diingati bagaimana cara menggunakan } \\
\text { sistem tersebut. }\end{array}$ & 0 & 0 & 1 & 4 & 25 & 4.8 \\
\hline 5 & $\begin{array}{l}\text { Sistem ini mesra pengguna. } \\
\text { Kekurangan media interaktif seperti video dan } \\
\text { gambar sebagai alat bantuan pembelajaran bahasa } \\
\text { isyarat. }\end{array}$ & 0 & 0 & 1 & 7 & 22 & 4.7 \\
\hline 7 & $\begin{array}{l}\text { Butang di dalam sistem ini semuanya berfungsi } \\
\text { dengan baik. }\end{array}$ & 0 & 0 & 2 & 8 & 20 & 4.6 \\
\hline 8 & $\begin{array}{l}\text { Warna dan bentuk yang digunakan untuk aplikasi ini } \\
\text { adalah menarik. }\end{array}$ & 0 & 0 & 2 & 7 & 21 & 4.6 \\
\hline 9 & $\begin{array}{l}\text { Saya dapat mencari media interaktif seperti gambar } \\
\text { dan video yang lengkap untuk pembelajaran. }\end{array}$ & 0 & 0 & 2 & 7 & 21 & 4.6 \\
\hline 10 & $\begin{array}{l}\text { Butang dan saiz huruf di dalam sistem tidak terlalu } \\
\text { kecik dan tidak terlalu besar. }\end{array}$ & 0 & 0 & 5 & 6 & 19 & 4.4 \\
\hline KESELURUHAN & & & & 4.57 \\
\hline
\end{tabular}

Jadual 3. Keberkesanan Sistem Terhadap Mobile Aplikasi "Pocket Lingua Sign" Menggunakan Perisian Kodular

\begin{tabular}{clcccccc}
\hline NO & \multicolumn{1}{c}{ PERKARA } & (1) & (2) & (3) & (4) & (5) & $\begin{array}{c}\text { SKOR } \\
\text { MIN }\end{array}$ \\
\hline 1 & $\begin{array}{l}\text { Lebih berkeyakinan untuk berkomunikasi setelah } \\
\text { mempelajari melalui aplikasi ini. }\end{array}$ & 0 & 0 & 1 & 6 & 23 & 4.7 \\
\hline 2 & $\begin{array}{l}\text { Saya boleh berkomunikasi dalam bahasa isyarat } \\
\text { setelah belajar melalui aplikasi ini. }\end{array}$ & 0 & 0 & 1 & 4 & 25 & 4.8 \\
\hline 3 & Aplikasi ini sesuai untuk semua golongan umur & 0 & 0 & 2 & 6 & 22 & 4.6 \\
\hline 4 & $\begin{array}{l}\text { Sistem ini membantu membuka mata masyarakat } \\
\text { berkenaan penggunaan bahasa isyarat }\end{array}$ & 0 & 0 & 1 & 4 & 25 & 4.8 \\
\hline 5 & $\begin{array}{l}\text { Sistem ini boleh menjadi platform pembelajaran } \\
\text { Bahasa Isyarat }\end{array}$ & 0 & 0 & 1 & 7 & 22 & 4.7 \\
\hline 6 & $\begin{array}{l}\text { Saya bersetuju aplikasi ini mampu meningkatkan } \\
\text { penguasaan saya terhadap bahasa isyarat. }\end{array}$ & 2 & 2 & 7 & 4 & 15 & 3.9 \\
\hline 7 & $\begin{array}{l}\text { Aplikasi ini memudahkan pencarian media } \\
\text { interaktif seperti video dan gambar. }\end{array}$ & 0 & 0 & 2 & 8 & 20 & 4.6 \\
\hline 8 & $\begin{array}{l}\text { Mempromosikan bahasa isyarat kepada } \\
\text { masyarakat }\end{array}$ & 0 & 0 & 2 & 7 & 21 & 4.6 \\
\hline 9 & $\begin{array}{l}\text { Aplikasi ini memudahkan saya mempelajari bahasa } \\
\text { isyarat }\end{array}$ & 0 & 0 & 2 & 7 & 21 & 4.6 \\
\hline 10 & $\begin{array}{l}\text { Kaedah pembelajaran dan isi kandungan bahasa } \\
\text { isyarat yang menarik }\end{array}$ & 0 & 0 & 5 & 6 & 19 & 4.4 \\
\hline & $\quad$ KESELURUHAN \\
\hline
\end{tabular}




\subsection{Perbincangan}

Penggunaan aplikasi bahasa isyarat ini dapat membantu dan membuka peluang kepada ramai masyarakat yang ingin mempelajari. Kajian ini juga bertujuan untuk mengenalpasti faktor aplikasi ini mampu meningkatkan penguasaan terhadap bahasa isyarat. Kajian lepas yang berbeza tidak menjadi halangan kepada pengkaji untuk memenuhi kehendak kajian. Analisis kajian juga mendapati setelah mempelajari menggunakan aplikasi ini ramai bersetuju pengguna lebih berkeyakinan untuk berkomunikasi setelah mempelajari melalui aplikasi ini. Dapat dirumuskan bahawa penggunaan aplikasi "Pocket Lingua Sign" ini banyak memberi impak positif kepada pengguna.

Antara implikasi dan cadangan kajian yang dibahaskan ialah implikasi terhadap kesedaran masyarakat tentang penggunaan bahasa isyarat, adalah:

1. Implikasi dan cadangan terhadap kelab di sekolah mahupun universiti

Dari sudut kesedaran kajian ini secara tidak langsung menarik golongan remaja untuk mempelajari bahasa isyarat. Mereka mendapat pendedahan dari awal lagi supaya mereka tidak kekok apabila mencuba bahasa isyarat. Malah, dengan adanya kelab bahasa isyarat di sekolah memberikan mereka pilihan untuk mencuba belajar Bahasa baru. Pihak sekolah boleh membantu dengan memperkenalkan aplikasi bahasa isyarat kepada mereka. Seiring peredaran zaman penggunaan telefon bimbit menjadi keutamaan. Aplikasi ini dapat mengisi masa lapang mereka.

2. Implikasi dan cadangan terhadap ibu bapa dan guru Sebelum diberikan pendedahan kepada pelajar, ibu bapa dan guru menjadi peranan penting dalam memperkenalkan kepada anak-anak mereka apa itu bahasa isyarat. Tetapi semuanya datang dari mereka dahulu. Aplikasi bahasa isyarat ini yang diberikan pendedahan kepada mereka secara tidak langsung penggunaan semakin meluas. Perkara ini tidak terhad kepada ibu bapa yang mempunyai masalah pendengaran dan percakapan sahaja. Malah, terbuka kepada semua golongan. Jika sebelum ini ibu bapa dan guru tidak tahu bahasa isyarat yang sesuai boleh digunakan maka aplikasi ini dapat memberi pendedahan awal.

3. Implikasi dan Cadangan kepada pensyarah

Berdasar dapatan kajian menunjukkan bahawa kebanyakan pelajar di university masih mengunakan modul pembelajaran. Kebanyakan pensyarah mempunyai kemahiran dalam menggunakan teknologi. Jadi, tidak asing sekiranya bentuk pembelajaran ditukar sepenuhnya kepada bentuk aplikasi. Hal ini juga memudahkan pelajar dalam membawa maklumat ke mana sahaja.

\section{Kesimpulan}

Kajian yang dijalankan ini telah dapat memberikan gambaran secara terperinci kepada proses pembangunan modul aplikasi bahasa isyarat menggunakan Pocket Lingua Sign. Batasan kajian ini boleh digunakan oleh pengkaji dalam membincangkan beberapa cadangan lanjutan yang boleh digunakan sebagai panduan kepada penyelidik akan datang. Kajian ini melibatkan aspek pemilihan seperti kerangka teori, sampel kajian dan sebagainya. Kajian ini mengambil sampel penilaian sebanyak 30 orang dari semua golongan masyarakat. Dicadangkan kajian yang akan datang dapat melibatkan penggunaan aplikasi menjadi maklumat pembelajaran terutama di bahagian Pendidikan seperti pelajar sekolah, pelajar universiti mahupun tenaga pengajar. Cadangan juga diberikan melalui isi kandungan aplikasi yang dapat menjadi lebih banyak dan padat. Aplikasi ini hanya memberikan asas bahasa isyarat seperti abjad, huruf dan cara komunikasi. Diharapkan pada masa akan dating isi kandungan menjadi lebih terperinci menjadikan pengguna tidak sukar mencari maklumat.

Aplikasi ini sedikit sebanyak menjimatkan masa dan memberi peluang kepada pengguna yang ingin belajar bahasa isyarat tetapi tidak berkesempatan. Kemudian, sistem ini telah mencapai objektif sistem di mana dapat membangunkan media interaktif seperti video dan gambar sebagai alat bantuan pembelajaran bahasa isyarat. Selain dapat memberikan pengetahuan dan kesedaran kepada masyarakat berkenaan penggunaan bahasa isyarat. Objektif terakhir Untuk menguji aplikasi ini mampu meningkatkan penguasaan terhadap bahasa isyarat. Sebelum mencapai kesemua objektif ini, beberapa kajian telah dilakukan terlebih dahulu.

\section{Rujukan}

[1] M. H. Pradikja, H. Tolle, and K. C. Brata, "Pengembangan Aplikasi Pembelajaran Bahasa Isyarat Berbasis Android Tablet”, JPTIIK, vol. 2, no. 8, 2018. 
[2] O. H. D. Khairul, "Penilaian Analisis Keperluan Kepada Penggunaan Bahasa Isyarat Bagi Orang Kurang Upaya (OKU) Kategori Masalah Pendengaran," Akademika, vol. 9, no. 1, pp. 51-61, 2020.

[3] A. Andreansyah, A. Rachman and R. R. Putri, "Implementation of Incremental Models on Development of Web-Based Loan Cooperative Applications," International Journal of Education, Science, Technology and Engineering, vol. 3, no. 1, pp. 26-34, 2020. 10.36079/lamintang.ijeste-0301.105.

[4] R. Wijayanti and S. Mulyati, "Rancangan Bangun Sistem Informasi Pemantauan Produksi dan Kegiatan antar Divisi", International Journal of Education, Science, Technology, and Engineering, vol. 1, no. 1, pp. 1-14, Dec. 2018.

[5] I. Y. Panessai, D. Iskandar, Afriani, Pratiwi, and E. Effendi, "Analisis Teknik Penerjemahan pada Abstrak Jurnal IJAI 6(1)", Journal of Humanities and Social Sciences, vol. 3, no. 1, pp. 9-22, Apr. 2021.

[6] T. I. Kusumawati, "Komunikasi Verbal dan Nonverbal," Jurnal Pendidikan Dan Konseling, vol. 6, no. 2, pp. 83-98, 2016.

[7] R. L. Delfanti, D. E. Piccioni, J. Handwerker, N. Bahrami, A. P. Krishnan, R. Karunamuni, J. A. Hattangadi-Gluth, T. M. Seibert, A. Srikant, K. A. Jones, V. S. Snyder, "Imaging Correlates for the 2016 Update on WHO Classification of Grade II/III Gliomas: Implications for IDH, 1p/19q and ATRX status," Journal of Neuro-Oncology, vol. 135, pages 601-609, 2017.

[8] S. Aisyah, A. L. Maimun, and N. Y. N. M. Rahimi, "Kepentingan Kebolehbacaan Buku Teks Dalam Dunia Pendidikan," Journal on Islam and Civilization, vol. 1, no. 1, pp. 25-40, 2007.

[9] I. Kurniawati, "Digitalisasi Buku Sekolah Sebagai Solusi Alternatif Permasalahan Pengadaan Buku Sekolah,” Journal Komunikasi, vol 16, pp. 364-376, 2012.

[10] P. Mandarani and Y. Putra, "Aplikasi Bahasa Isyarat Untuk Tuna Rungu,", JTIP, vol. 8, no. 1, pp. 47-52, 2020.

[11] N. Aziz, A. C. Omar, A. A. Mutalib, S. Z. Ahmad, M. A. Muin and S. A. Annamalai, "Uncovering the Needs for a Hybridized Interaction Design Model for Sign Language Learning Through Experts' Feedback," Journal of Physics: Conference Series, vol. 1529. pp. 1-10, 2020.

[12] S. Nasional, S. Nita, A. D. Cahyanti, F. Teknik, F. Teknik and T. Indonesia, "Penggunaan Aplikasi I-Chat Sebagai Sarana Teknologi", eminar Nasional Hasil Penelitian dan Pengabdian kepada Masyarakat UNIPMA, pp. 174-180, 2019.

[13] M. Azmi, H. Joebagio and N. Suryani, "Studi Pendahuluan Pengembangan Aplikasi Smartphone Sebagai Alternatif Media Pembelajaran Sejarah," Vidya Karya, vol. 31, no. 1, pp. 57- 63, 2017.

[14] L. A. Sandy, R. J. Akbar and R. R. Hariadi, "Rancang Bangun Aplikasi Chat Pada Platform Android Dengan Media Input Berupa Canvas Dan Shareable Canvas Untuk Bekerja Dalam Satu Canvas Secara Online", Jurnal Teknik, vol. 6, no. 2, 2017.

[15] A. Helmond, "The Platformization of the Web: Making Web Data Platform Ready," Social Media and Society, vol. 1, no. 2. , 2015.

[16] A. Sagiyanto and N. Ardiyanti, "Self Disclosure Melalui Media Sosial Instagram (Studi Kasus Pada Anggota Galeri Quote)", Journal of Communication, vol. 2, no. 1, pp. 81-94, 2018.

[17] I. Irwandani and S. Juariyah, "Pengembangan Media Pembelajaran Berupa Komik Fisika Berbantuan Sosial Media Instagram Sebagai Alternatif Pembelajaran", Jurnal Ilmiah Pendidikan Fisika Al-Biruni, vol. 5, no. 1, pp. 33, 2016.

[18] N. Khairuni, "Dampak Positif Dan Negatif Sosial Media Terhadap Pendidikan Akhlak Anak (Studi Kasus di SMP Negeri 2 Kelas VIII Banda Aceh)," Jurnal Bimbingan Konseling, vol. 2, no. 1, pp. 91, 2016.

[19] E. M. Fitria, "Dampak Online Shop Di Instagram Dalam Perubahan Gaya Hidup Konsumtif Perempuan Shopaholic Di Samarinda”, E-Jurnal Ilmu Komunikasi, vol. 1, no. 3, pp. 117-128, 2015.

[20] W. A. Luqyana, I. Cholissodin and R. S. Perdana, "Analisis Sentimen Cyberbullying Pada Komentar Instagram Dengan Metode Klasifikasi Support Vector Machine", Jurnal Pengembangan Teknologi Informasi dan Ilmu Komputer (J-PTIIK) Universitas Brawijaya, vol. 2, no. 11, pp. 4704-4713, 2018.

[21] N. Hussin, M. S. Rasul, and R. A. Rauf, "Penggunaan Laman Web Sebagai Transformasi dalam Pengajaran dan Pembelajaran Pendidikan Islam", OnlineJournal of Islamic Education, vol. 1, no. 2, pp. 58-73, 2013.

[22] M. N. Jaffar and A. Sha'ari. "Penggunaan Laman Web I-Majrurat Sebagai Alat Bantu Mengajar 
Tatabahasa Arab", Al-Qanatir International Journal of Islamic Studies, vol. 3, no. 1, pp. 1-8, 2016.

[23] K. Arofah, "Youtube Sebagai Media Klarifikasi dan Pernyataan Tokoh Politik," Jurnal Ilmu Komunikasi, vol. 13, no. 2, 2015.

[24] N. Aripin, A. Ismail, M. Ishak, N. Rahman, M. Rahman, M. Madon and M. Mustaffa, "Youtube" Dan Generasi Muda Islam: Satu Pendekatan Kelompok Fokus Dalam Kalangan Pelajar Universiti. Jurnal Komunikasi”, Malaysian Journal of Communication, vol. 32, no. 1, pp. 165 $188,2016$.

[25] I. L. Y. Bagut, "Penggunaan Bahasa dalam Iklan Minuman di Youtube," ALFABETA, vol.2, no. 2, 2019.

[26] S. Wigati, Pengembangan Youtube Pembelajaran Berbasis Ajaran Ki Hadjar Dewantara Untuk Materi Integral Tak Tentu Di Sma, Skripsi, Universitas UST, Yogyakarta, 2018.

[27] S. Surahman and E. Setiawan, "Aplikasi Mobile Driver Online Berbasis Android Untuk Perusahaan Rental Kendaraan”, Ultima InfoSys: Jurnal Ilmu Sistem Informasi, vol. 8, no. 1, pp. 35-42, Jun. 2017.

[28] S. Surahman and E. B. Setiawan, "Aplikasi Mobile Driver Online Berbasis Android Untuk Perusahaan Rental Kendaraan", vol. 1, 2017.

[29] N. H. Rahani, A. A. Bilong, M. R. Suruji, I. Y. Panessai, "Learning Logic Gates Using Augmented Reality", International Journal of Multimedia and Recent Innovation, vol. 2, no. 1, pp. 26-44, 22 Mar 2020.

[30] M. Wedel, E. Bigné, J. Zhang, "Virtual and augmented reality: Advancing research in consumer marketing", International Journal of Research in Marketing, vol. 37, no. 3, pp. 44-65, Sep 2020.

[31] N. A Ibharim, S. Z. Ramli, S. A. Zahari, N. A. Edyanto, M. A. Zawawi, "Learning History Using Augmented Reality", International Journal of Multimedia and Recent Innovation, vol. 3, no. 1, pp. 1-10, 14 Mar 2021.

[32] A. Ismail, "An Early Development Process of an Augmented Reality-Based Healthy Diet Tool Prototype", International Journal of Multimedia and Recent Innovation, vol. 26, no. 22, pp. 96101, Sep 2020

[33] N. A. Edyanto, S. Z. Ramli, N. A. Ibharim, S. A. Zahari, M. A. Zawawi, "Learn Idioms Using Augmented Reality", International Journal of Multimedia and Recent Innovation, vol. 3, no. 1, pp. 11-6, 14 Mar 2021.

[34] Z. Z. Abidin, M. A. Zawawi, "OOP-AR: Learn Object Oriented Programming Using Augmented Reality", International Journal of Multimedia and Recent Innovation, vol. 2, no. 1, pp. 60-75, 22 March 2020.

[35] F. D. Putra, J. Riyanto, A. F. Zulfikar, "Rancang Bangun Sistem Informasi Manajemen Aset pada Universitas Pamulang Berbasis WEB", Journal of Engineering, Technology, and Applied Science. vol. 2, no. 1, pp. 32-50, 6 Apr 2020.

[36] F. Mantiri, "Multimedia and Technology in Learning", Universal Journal of Educational Research. vol. 2, no. 9, pp. 589-92, 2014.

[37] M. Bernarducci, "Multimedia for Learning: Methods and Development -Book Review", European Journal of Education Studies, 16 March 2017.

[38] N. F. Zakaria, Z. Z. Abidin, M. A. Zawawi, S. N. Shuhada, "Bloodbuddy: a Tracking System for Blood Donor Using GPS", Journal of Engineering, Technology, and Applied Science. vol. 2, no. 2, pp. 86-102, 30 Aug 2020.

[39] N. H. Hasbullah, N. A. Noor, "Sistem Temujanji Interaktif Berasaskan WEB", Journal of Engineering, Technology, and Applied Science, vol. 2, no. 3, pp. 110-7, 17 Dec 2020.

[40] M. Olva, R. D. Permatasari, S. Majid, P. Syair, A. Suganda, "Pemanfaatan Dasbor pada Pemantauan Data Transaksi Penjualan", Journal of Engineering, Technology, and Applied Science, vol. 3, no. 1, pp. 1-5, 14 Apr 2021. 